\title{
Regulatory Action of Plasma from Patients with Obesity and Diabetes towards Muscle Cells Differentiation and Bioenergetics Revealed by the C2C12 Cell Model and MicroRNA Analysis
}

\author{
Natalya V. Khromova ${ }^{1, *, \dagger}$, Anton V. Fedorov ${ }^{1,+}{ }^{\dagger}$ Yi Ma ${ }^{1}$, Kirill A. Kondratov ${ }^{1}$, Stanislava S. Prikhodko ${ }^{1}$, \\ Elena V. Ignatieva ${ }^{1}$, Marina S. Artemyeva ${ }^{1}$ (D) Anna D. Anopova ${ }^{1}{ }^{\mathbb{D}}$, Aleksandr E. Neimark ${ }^{1}$, \\ Anna A. Kostareva ${ }^{1,2}{ }^{\mathbb{D}}$, Alina Yu. Babenko ${ }^{1}$ and Renata I. Dmitrieva ${ }^{1} \mathbb{D}$ \\ 1 National Almazov Medical Research Centre, Institute of Molecular Biology and Genetics, \\ 197341 Saint-Petersburg, Russia; antonfedorow@gmail.com (A.V.F.); mayi29082@yandex.ru (Y.M.); \\ kondratovk.kirill@yandex.ru (K.A.K.); stanislava.prikhodko@gmail.com (S.S.P.); \\ ignateva_ev@almazovcentre.ru (E.V.I.); marinaart888@mail.ru (M.S.A.); anopova.ann@gmail.com (A.D.A.); \\ neymark_ae@almazovcentre.ru (A.E.N.); anna.kostareva@ki.se (A.A.K.); alina_babenko@mail.ru (A.Y.B.); \\ renata.i.dmitrieva@gmail.com (R.I.D.) \\ check for \\ updates \\ Citation: Khromova, N.V.; Fedorov, \\ A.V.; Ma, Y.; Kondratov, K.A.; \\ Prikhodko, S.S.; Ignatieva, E.V.; \\ 2 Center for Molecular Medicine, Department of Women's and Children's Health, Karolinska Institute \\ 17177 Stockholm, Sweden \\ * Correspondence: khromova@almazovcentre.ru \\ $+\quad$ These authors contributed equally to this work.
} Artemyeva, M.S.; Anopova, A.D.; Neimark, A.E.; Kostareva, A.A.; et al Regulatory Action of Plasma from Patients with Obesity and Diabetes towards Muscle Cells Differentiation and Bioenergetics Revealed by the C2C12 Cell Model and MicroRNA Analysis. Biomolecules 2021, 11, 769. https://doi.org/10.3390/biom 11060769

Academic Editor: Cristina M. Ramírez Hidalgo

Received: 1 April 2021

Accepted: 17 May 2021

Published: 21 May 2021

Publisher's Note: MDPI stays neutral with regard to jurisdictional claims in published maps and institutional affiliations.

Copyright: (c) 2021 by the authors. Licensee MDPI, Basel, Switzerland. This article is an open access article distributed under the terms and conditions of the Creative Commons Attribution (CC BY) license (https:/ / creativecommons.org/licenses/by/ $4.0 /)$.

\begin{abstract}
Obesity and type 2 diabetes mellitus (T2DM) are often combined and pathologically affect many tissues due to changes in circulating bioactive molecules. In this work, we evaluated the effect of blood plasma from obese (OB) patients or from obese patients comorbid with diabetes (OBD) on skeletal muscle function and metabolic state. We employed the mouse myoblasts $\mathrm{C} 2 \mathrm{C} 12$ differentiation model to test the regulatory effect of plasma exposure at several levels: (1) cell morphology; (2) functional activity of mitochondria; (3) expression levels of several mitochondria regulators, i.e., Atgl, $\mathrm{Pgc1b}$, and miR-378a-3p. Existing databases were used to computationally predict and analyze mir-378a-3p potential targets. We show that short-term exposure to OB or OBD patients' plasma is sufficient to affect $\mathrm{C} 2 \mathrm{C} 12$ properties. In fact, the expression of genes that regulate skeletal muscle differentiation and growth was downregulated in both OB- and OBD-treated cells, maximal mitochondrial respiration rate was downregulated in the OBD group, while in the OB group, a metabolic switch to glycolysis was detected. These alterations correlated with a decrease in ATGL and Pgc1b expression in the OB group and with an increase of miR-378a-3p levels in the OBD group.
\end{abstract}

Keywords: murine myoblast cell line; mitochondria; miR-378a-3p; skeletal muscle differentiation; skeletal muscle bioenergetics; plasma; obesity; diabetes

\section{Introduction}

Over the past few decades, a dramatic worldwide increase in the incidence of obesity and diabetes mellitus type 2 (DM2) has been observed. More than 600 million people suffer from obesity [1], and about 400 million have T2DM [2]; these two pathologies are closely related, since one-third of obese patients suffer from T2DM, while about $80 \%$ of T2DM patients are overweight [3-5].

Both obesity and T2DM pathologically affect many tissues, including skeletal muscles, causing severe functional and metabolic changes. It is well documented that skeletal muscle pathological changes common in obesity include morphological and metabolic alterations, sarcopenia, a shift towards a fast-switch fiber phenotype, a decline in the 
contractile function [6-12]. Moreover, obesity can lead to the impairments in molecular mechanisms that regulate skeletal muscle satellite cells activation, which results in altered mechanisms of skeletal muscle regeneration, development, and contractile activity $[13,14]$.

Because muscle tissue occupies a significant part of the human body, it is one of the main regions of glucose consumption and is notably affected by T2DM. It has been shown that T2DM induces atrophy [15-17], fiber-type transition from oxidative to glycolytic [18,19], and impaired energy metabolism in skeletal muscle [20-22]. These alterations result in skeletal muscle dysfunction, such as muscle weakness and exercise intolerance $[17,23]$.

It is well known that skeletal muscle is a plastic tissue that easily adapts to changes in energy status due to changes in mitochondria. In healthy individuals, mitochondria are able to switch between carbohydrate and lipid fuels to produce energy in conditions of fasting or nutrients overload. Skeletal muscle of T2DM patients has reduced mitochondrial content $[22,24,25]$. In patients with insulin resistance, the oxidative capacity of mitochondria is lower than in healthy people, and these changes lead to the accumulation of fat in skeletal tissue [22]. The regulatory signal transmitted to skeletal muscles can be disrupted by changes in the profile of molecules circulating in the plasma, which happens in metabolic disorders [3,4].

In this work, we evaluated the effects of plasma from obese patients and obese patients comorbid with TDM2 on muscle cells functionality. We employed the mouse myoblasts C2C12 differentiation model to test the regulatory effect of patients' plasma at several levels: (1) cell morphology, (2) functional activity of mitochondria, (3) expression levels of several mitochondria regulators, i.e., Atgl, $P g c 1 b$, and miR-378-3p. Mitochondria regulators were selected from the Atgl-mediated fat catabolism pathway which was described to control mitochondria function in mouse cardiac muscle and depends on Atgl-mediated fatty acid fluxes from lipid droplets [26]. Atgl is a rate-limiting enzyme in triacylglycerol hydrolysis, which mediates the production of free fatty acids (FFA) from lipids [27]. FFA represent a substrate for b-oxidation and serve as regulatory ligands for PPARs transcription factors [28]. The transcription factor Pgc1b is a downstream target of PPAR, involved in the coordination of multiple processes in mitochondria, including mitochondrial biogenesis and glucose and fatty acid metabolism [29]. Notably, the first intron of Pgc1b encodes miR378 a, which is also known to regulate glucose and fatty acid metabolism and counteract the action of $P g c 1 b$ on mitochondria activity [30].

\section{Materials and Methods}

\subsection{Study Population}

The study was approved by the Ethics Committee of the Almazov National Medical Research Centre (Ref. \# 54/14.03.2016) and was conducted in compliance with current Good Clinical Practice standards and in accordance with the principles under the Declaration of Helsinki (1989). All patients entering the program agreed to and signed an institutional review board-approved statement of informed consent.

\subsection{Cell Culture and Myogenic Differentiation}

The C2C12 mouse myoblasts cell line was purchased from ATCC (ATCC CRL-1772). $\mathrm{C} 2 \mathrm{C} 12$ cells were handled as recommended by the manufacturer: cells were cultured in proliferation medium (DMEM supplemented with $4.5 \mathrm{~g} / \mathrm{L}$ D-glucose, L-glutamine, penicillin-streptomycin, and 20\% fetal calf serum (FCS)) and were passaged at $60-80 \%$ of confluence. Fusion of some cells without external stimuli usually was observed in sub-confluent cultures and served as a reliable indicator of myogenic commitment, after which we induced differentiation. To induce differentiation, at day 0 the proliferation medium was replaced with differentiation medium (DMEM medium supplemented with $4.5 \mathrm{~g} / \mathrm{L}$ D-glucose, L-glutamine, penicillin-streptomycin, and $2 \%$ horse serum (HS)). The differentiation medium replaced every day; at day 2, after medium replacement, human plasma from healthy volunteers or from patients with obesity and obesity comorbid with diabetes was added to the cultures, as indicated in the corresponding figures' legends. 
Cells were harvested, and RNA was extracted for expression analysis on days 0, 2, and 3 . Immunocytochemistry was performed on day 4 after stimulation of differentiation.

\subsection{Plasma Samples Preparation}

The blood samples were collected in EDTA tubes, plasma was separated within $2 \mathrm{~h}$ after blood collection by two rounds of centrifugation at $1600 \mathrm{~g}$ for $10 \mathrm{~min}$; supernatant was aliquoted and stored at $-80^{\circ} \mathrm{C}$ for further processing. For cell culture experiments, samples of plasma were prepared as follows: plasma was thawed, centrifuged at $3000 \mathrm{~g}$ for $10 \mathrm{~min}$ in order to remove the crude pellet; then, centrifugation of the supernatant at $20,000 \mathrm{~g}$ for $20 \mathrm{~min}$ was performed. The obtained supernatant fractions were heated at $55^{\circ} \mathrm{C}$ for $30 \mathrm{~min}$ to inactivate the complement system and stored at $-80^{\circ} \mathrm{C}$ until use.

\subsection{C2C12 Treatment with Plasma}

The design of the study is summarized in Figure 1. In order to test how cell-free components of blood from patients with obesity and comorbid diabetes affect skeletal muscle development and functions, we compared the effect of plasma from healthy volunteers $(C)$, patients with obesity $(\mathrm{OB})$, or patients with obesity comorbid with diabetes $(\mathrm{OBD})$ on gene expression and morphology of mouse myoblasts $\mathrm{C} 2 \mathrm{C} 12$ during myogenic differentiation.

Each sample for cells treatment consisted of pooled plasma from two patients. Plasma was added on day 2 after induction of myogenic differentiation, the time point when the transition between early and late steps of differentiation was observed in our cultures, as described below. RNA samples were collected on days 0,2 , and 3 in order to test the effect of plasma on the dynamics of expression of genes that control mitochondria function and skeletal muscle regeneration and development. In addition, on day 4, differentiated myotubes were fixed and immunostained in order to evaluate myoblast fusion and myotube morphology.

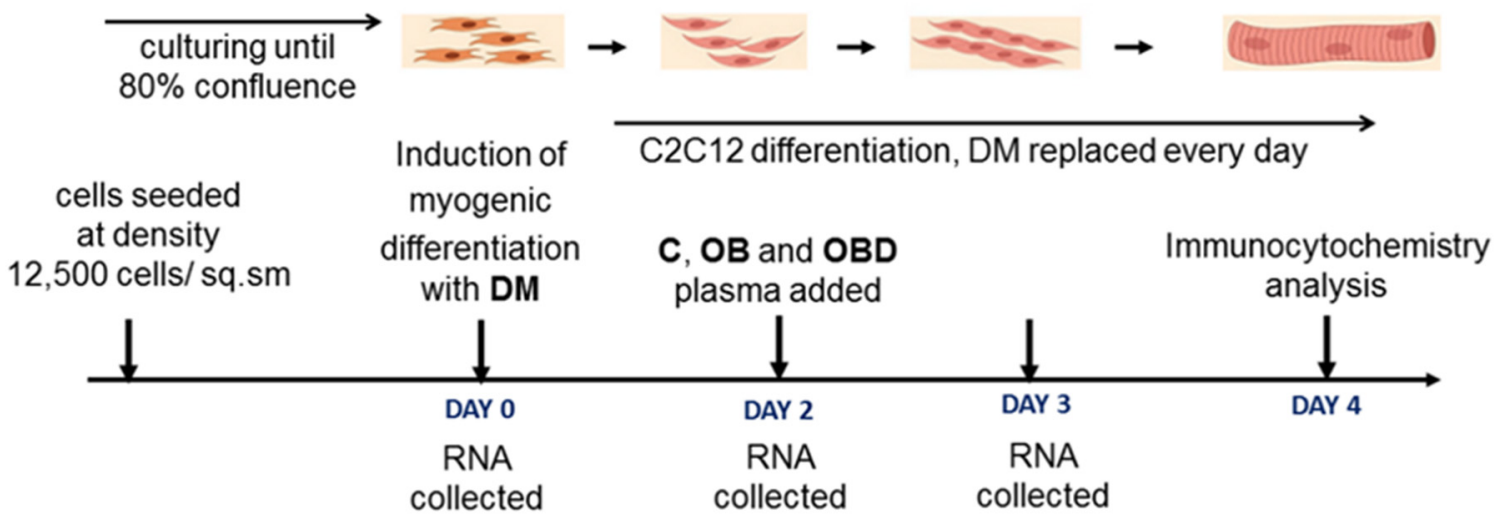

Figure 1. Study design. DM-differentiation medium; plasma from healthy volunteers $(C)$, obese patients (OB), and obese patients comorbid with diabetes (OBD).

\subsection{Immunocytochemistry}

Cells were grown and differentiated on cover glasses and stained as recommended by the antibody manufacturer. Briefly, cells were washed with PBS buffer, fixed in $4 \%$ paraformaldehyde for $10 \mathrm{~min}$ at $4{ }^{\circ} \mathrm{C}$, permeabilized with $0.02 \%$ Triton $\mathrm{X}-100$ for $5 \mathrm{~min}$. Nonspecific binding was blocked by incubation in $15 \%$ FCS for $30 \mathrm{~min}$ followed by incubation for one hour with primary anti-myosin heavy chain antibodies (MF20, MAB4470, R\&D, USA). Secondary antibodies conjugated with/Alexa-488 (Molecular Probes, Eugene, OR, USA) were applied for $45 \mathrm{~min}$ at room temperature. Nuclei were counterstained with DAPI (Molecular Probes, Eugene, OR, USA). 


\subsection{RNA Isolation and Quantification of $m R N A$ of Protein-Coding Genes}

Total RNA was isolated using ExtractRNA reagent (Evrogen, cat.no. BC032, Moscow, Russia). cDNA was synthesized from 500 ng of total RNA using a Moloney Murine Leukemia Virus Reverse Transcriptase MMLV RT kit (Evrogen, SK021, Moscow, Russia). A quantitative evaluation of gene expression was performed with qPCR mix-HS SYBR+ROX (Evrogen, cat.no. PK156, Moscow, Russia). Sequences for primers for target amplification are given in Table 1. RT-qPCR data are presented as relative mRNA levels normalized to the geometric mean of the reference transcripts Gapdh and Actb. All further details are given in corresponding figures' legends.

Table 1. Sequences for primers.

\begin{tabular}{|c|c|}
\hline Target & Sequence $5^{\prime}-3^{\prime}$ \\
\hline Myh1 forward & GCTGAGAGAAGCTACCACATT \\
\hline Myh1 reverse & ACAAAGGCGTAGTCGTATGG \\
\hline Myh7 forward & TGCCCGATGACAAAGAAGAG \\
\hline Myh7 reverse & GTCACCGTCTTGCCATTCT \\
\hline Mymk forward & CCTGTGATGGGCCTGGTTTGTC \\
\hline Mymk reverse & GGTTCATCAAAGTCGGCCAGTGC \\
\hline MyoD forward & TGCCTTCTACGCACCTGGA \\
\hline MyoD reverse & CGCTGTAATCCATCATGCCATC \\
\hline Atgl forward & CCACTTTAGCTCCAAGGATGAG \\
\hline Atgl reverse & TTGGAGGGTAGGAGGAATGA \\
\hline Pgc1b forward & СТTТАТСТСТTССТСТGAССССАG \\
\hline Pgc1b reverse & CCAGAGAGTTCCACACTTAAGGTT \\
\hline Gapdh forward & GGATCTGACGTGCCGCCTG \\
\hline Gapdh reverse & GAAGGTGGA AGAGTGGGAGTTGC \\
\hline
\end{tabular}

\subsection{MicroRNA Quantification}

MicroRNA quantification was performed as described previously [31]. Briefly, for the amplification of microRNAs, TaqMan Universal Master Mix II no UNG and the corresponding TaqMan Assay (Thermo Fisher Scientific, Waltham, MA, USA, ) were used as recommended by the manufacturer. TagMan Assay 001314 was used to detect miR-378a-3p, and Rn00667869_m1 was used to detect to Actb. All further details are given in the figures' legends.

\subsection{Bioinformatic Analysis and Statististics}

TargetScan (http:/ / www.targetscan.org/, accessed on 7 May 2021) [32] and miRDB (http://mirdb.org/, accessed on 7 May 2021) [33] databases were used as sources of computationally predicted targets of microRNA. Enrichment analysis was performed using GO Biological Process pathways gene-set libraries, with ENRICHR software (https: / / maayanlab.cloud/Enrichr/, accessed on 7 May 2021) [34].

Statistical analysis was carried out using GraphPad Prism 5 software (San Diego, CA, USA). Baseline patients' characteristics and mean and standard deviation are presented. U-Mann-Whitney test was used to assess differences between the means of two groups. Spearman correlation coefficient was calculated to analyze the relationship between two parameters. $p$ values less than 0.01 for enrichment analysis and less than 0.05 for the other experiments were considered statistically significant.

\section{Results}

3.1. Description of Patients, Baseline Characteristics

In total, 18 patients were included in this project. All of them were female, 10 recruited patients were obese (BMI $>30 \mathrm{~kg} / \mathrm{m}^{2}$ ) (OB group), and 8 had type 2 diabetes mellitus (T2DM) comorbid with obesity (OBD group). Ten healthy female-volunteers with $\mathrm{BMI}<18-25 \mathrm{~kg} / \mathrm{m}^{2}$ ) were included in the control group (C group). Participants' clinical characteristics are summarized in Table 2. 
Patients with T2DM comorbid with obesity (group OBD) were on metformin treatment monotherapy. Patients with other clinically significant comorbidities and taking drugs that affect body weight (antidepressants, antipsychotics, anorectics) were excluded from the study.

Healthy volunteers were younger ( $36.7 \pm 8.5$ years) than patients in the $\mathrm{OB}$ and $\mathrm{OBD}$ groups ( $48.0 \pm 10.5$ years; $52.4 \pm 10.4$ years, respectively) $(p<0.05)$, while the age of the patients did not differ between the OB and OBD groups. The BMI of patients in the OB and OBD groups did not differ $\left(47.3 \pm 8.6 \mathrm{~kg} / \mathrm{m}^{2} ; 50.4 \pm 10.3 \mathrm{~kg} / \mathrm{m}^{2}\right.$, respectively) and was higher than the BMI of volunteers in the control group $\left(21.8 \pm 2.2 \mathrm{~kg} / \mathrm{m}^{2} ; p<0.001\right)$. The $\mathrm{HbA1c}$ and glucose levels were significantly higher in OBD patients than in OB patients: $7.5 \pm 1.4 \%$ vs. $5.49 \pm 0.4 \%(p<0.01)$ and $5.87 \pm 0.5 \mathrm{mmol} / \mathrm{L}$ vs. $9.0 \pm 2.9 \mathrm{mmol} / \mathrm{L}$ $(p<0.005)$, respectively. Similar BMI was used as the criterion for plasma pooling, as indicated in the column Pool_ID of Table 2.

Table 2. Patients' characteristics.

\begin{tabular}{|c|c|c|c|c|c|c|c|c|c|}
\hline $\begin{array}{l}\text { Group of } \\
\text { Patients }\end{array}$ & Patiet ID & $\begin{array}{c}\text { Age } \\
\text { (Years) }\end{array}$ & $\begin{array}{c}\text { BMI } \\
\left(\mathrm{kg} / \mathrm{m}^{2}\right)\end{array}$ & $\begin{array}{l}\text { Obesity } \\
\text { Grade }\end{array}$ & $\begin{array}{c}\text { Diabetes } \\
\text { Duration } \\
\text { (Years) }\end{array}$ & $\begin{array}{c}\text { HbA1c } \\
\text { Levels } \\
(\%)\end{array}$ & $\begin{array}{c}\text { Glucose } \\
\text { Levels } \\
(\mathrm{mmol} / \mathrm{L})\end{array}$ & Pool_ID & Pool_BMI \\
\hline \multirow{10}{*}{ Control (C) } & $\mathrm{c} 1$ & 26 & 16.9 & NA & NA & 5.2 & 5.06 & $\mathrm{C} 1$ & 18.7 \\
\hline & $\mathrm{c} 2$ & 26 & 20.6 & NA & NA & 4.5 & 4.65 & $\mathrm{C} 1$ & 18.7 \\
\hline & c8 & 43 & 20.7 & NA & NA & 5.5 & 5.24 & $\mathrm{C} 2$ & 21.0 \\
\hline & $\mathrm{c} 11$ & 38 & 21.3 & NA & NA & 4.7 & 4.9 & $\mathrm{C} 2$ & 21.0 \\
\hline & c9 & 45 & 22.2 & NA & NA & 5.1 & 5.0 & C3 & 22.2 \\
\hline & c4 & 50 & 22.2 & NA & NA & 5.1 & 5.38 & $\mathrm{C} 3$ & 22.2 \\
\hline & c10 & 32 & 22.4 & NA & NA & 5.0 & 5.38 & $\mathrm{C} 4$ & 22.9 \\
\hline & c5 & 44 & 23.4 & NA & NA & 5.6 & 5.24 & $\mathrm{C} 4$ & 22.9 \\
\hline & c7 & 33 & 24.1 & NA & NA & 4.5 & 4.39 & C5 & 24.2 \\
\hline & c3 & 30 & 24.4 & NA & NA & 4.5 & 4.39 & $\mathrm{C} 5$ & 24.2 \\
\hline \multirow{10}{*}{ Obesity (OB) } & B122 & 40 & 40.2 & III & NA & 5.75 & 6.29 & OB1 & 40.6 \\
\hline & B136 & 35 & 40.9 & III & NA & 5.14 & 6.18 & OB1 & 40.6 \\
\hline & B130 & 57 & 41.2 & III & NA & 5.4 & 5.06 & OB2 & 41.7 \\
\hline & B131 & 61 & 42.2 & III & NA & 5.7 & 5.9 & OB2 & 41.7 \\
\hline & B141 & 40 & 43.9 & III & NA & 5.6 & 5.8 & OB3 & 44.4 \\
\hline & B164 & 53 & 44.8 & III & NA & 5.5 & 5.63 & OB3 & 44.4 \\
\hline & B160 & 34 & 46 & III & NA & 5.0 & 5.18 & OB4 & 48.2 \\
\hline & B151 & 60 & 50.4 & III & NA & 5.3 & 5.99 & OB4 & 48.2 \\
\hline & B147 & 56 & 56.4 & III & NA & 5.2 & 5.8 & OB5 & 61.9 \\
\hline & B124 & 44 & 67.3 & III & NA & 6.4 & 6.84 & OB5 & 61.9 \\
\hline \multirow{8}{*}{$\begin{array}{c}\text { Obesity } \\
\text { comorbid } \\
\text { with diabetes } \\
(\mathrm{OBD})\end{array}$} & B158 & 60 & 36.2 & II & 8 & 6.2 & 8.77 & OBD1 & 37.6 \\
\hline & B202 & 61 & 38.9 & II & 17 & 6.8 & 9.07 & OBD1 & 37.6 \\
\hline & B174 & 46 & 47.2 & III & 13 & 6.8 & 6.63 & OBD2 & 48.1 \\
\hline & B169 & 66 & 48.9 & III & 7 & 7.09 & 7.19 & OBD2 & 48.1 \\
\hline & B168 & 56 & 49.8 & III & 3 & 7.87 & 8.35 & OBD3 & 51.8 \\
\hline & B128 & 39 & 53.8 & III & 5 & 9.2 & 12.58 & OBD3 & 51.8 \\
\hline & B112 & 53 & 63.2 & III & 7 & 6.56 & 5.25 & OBD4 & 64.2 \\
\hline & B142 & 38 & 65.1 & III & 7 & 10.05 & 14.49 & OBD4 & 64.2 \\
\hline
\end{tabular}

Obesity grade II $\left(35.0 \leq \mathrm{BMI} \leq 39.9 \mathrm{~kg} / \mathrm{m}^{2}\right)$ and obesity grade $\mathrm{III}\left(\mathrm{BMI} \geq 40.0 \mathrm{~kg} / \mathrm{m}^{2}\right)$. 
3.2. Plasma from Obese Patients (OB) and Patients with Type 2 Diabetes Comorbid with Obesity (OBD) Affects the Expression of Mymk and the Composition of Myofiber Types during Skeletal Muscle Differentiation

First, we tested how plasma from obese patients (OB) and patients with type 2 diabetes comorbid with obesity (OBD) affect skeletal muscle growth and development using the C2C12 mouse myoblasts differentiation model. In order to choose the best time point to treat the differentiating $\mathrm{C} 2 \mathrm{C} 12$ myoblasts, we determined when transition from early to late stage of differentiation occurs. In $\mathrm{C} 2 \mathrm{C} 12$ cultures treated with differentiation medium, there is a well-coordinated pattern of expression of the genes MyoD [35] and Mymk, [36] which regulate early events of myogenesis, and of those for myosins Myh1/Myh7, which indicate the successful transition to the myofiber maturation stage of myogenesis [35]. Here, we show that expression of the myogenic regulatory factor gene $M y o D$ and of the gene Mymk that regulates myoblast fusion strongly increased during transition from day 0 to day 2 and then either remined at the same level $(M y o D)$ or showed a small but significant increase by day 3 (Mymk) (Figure 2A,B; green label). On the contrary, the expression of the fast-twitch fiber marker Myh1 and of the slow-twitch fiber marker Myh7 showed a stable increase during transition from day 0 to day 3 (Figure 2C,D; green label). Together, these data show that the transition between the early steps of differentiation to fiber growth and maturation occurred in our C2C12 myoblasts between day 2 and day 3 after stimulation; therefore, we chose day 2 as the most appropriate time for plasma treatment.
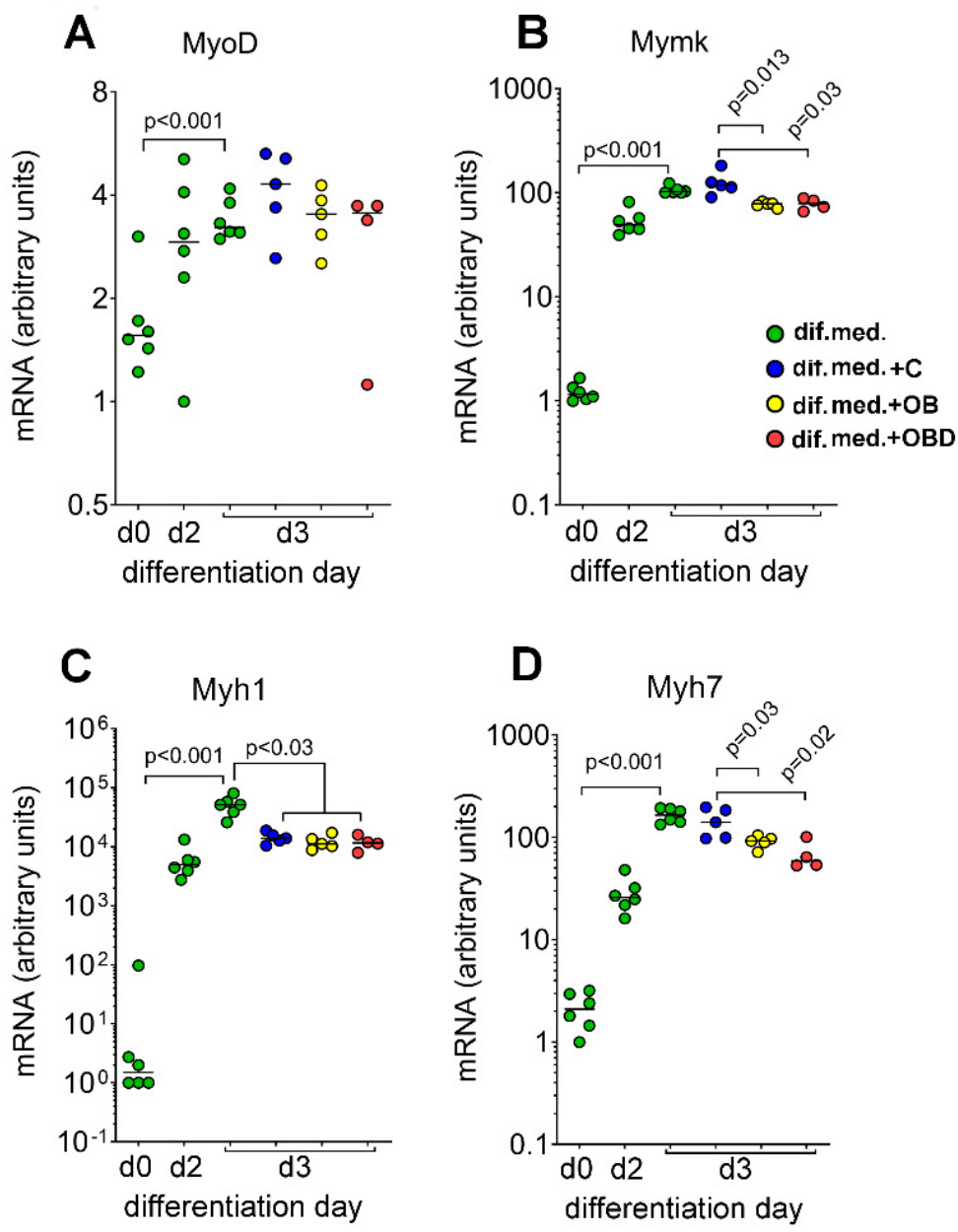

Figure 2. Effects of plasma from obese patients $(\mathrm{OB})$, patients with type 2 diabetes comorbid with obesity (OBD), and healthy volunteers (C) on the expression of markers of myogenic differentiation in C2C12 myoblasts. (A) Myogenic regulatory factor MyoD; (B) muscle-specific myoblast fusion regulator Mymk; (C) fast-glycolytic fiber Myh1 isoform; (D) oxidative-slow fiber Myh7 isoform. 
The analysis of the expression of genes that control myogenesis during the transition from day 2 to day 3 of myogenic differentiation revealed substantial alterations: while the expression of $M y o D$ did not differ in cells subjected to different treatments (DifMed/C/OB/OBD, Figure 2A), the expression of Mymk was downregulated by OB/OBD plasma, but not by plasma from healthy volunteers (C) (Figure 2B). Furthermore, in all plasma-treated samples, we detected downregulated expression of fast-twitch glycolytic $M y h 1$, while the expression of slow-twitch oxidative Myh7 was downregulated in cultures treated with OB/OBD plasma in comparison to DifMed/C cultures (Figure 2C,D).

The differences in morphology of $\mathrm{C} 2 \mathrm{C} 12$ myotubes treated with $\mathrm{C} / \mathrm{OB} / \mathrm{OBD}$ plasma confirmed the alterations in myoblasts fusion activity in OB/OBD-treated cultures: the width of OB/OBD-treated myotubes was significantly smaller than that of C-treated myotubes, and the fraction of tubules with a high number of nuclei was larger in C-treated myotubes (Figure 3A-C).
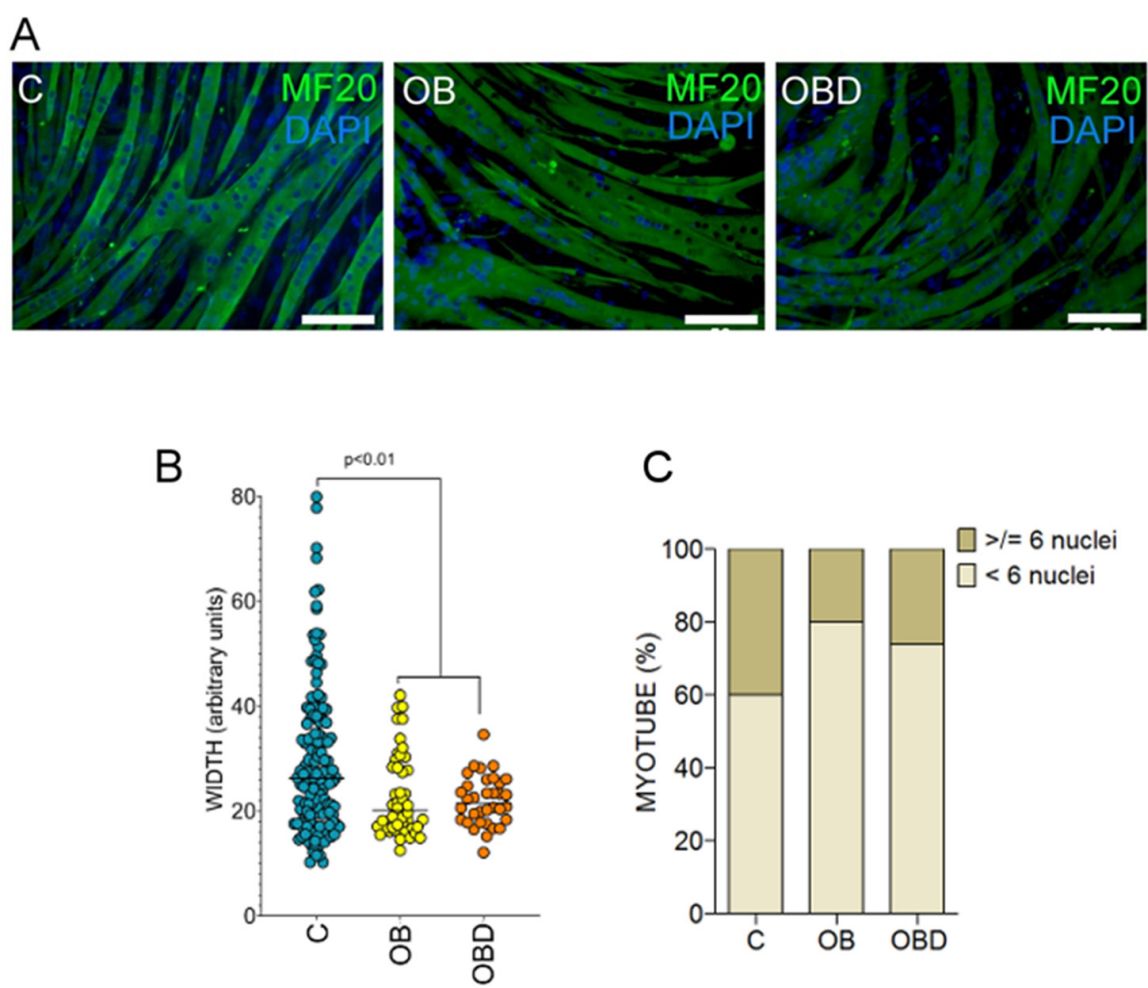

Figure 3. Myotubes morphology and fusion coefficient. (A) Immunocytological staining of differentiated myotubes with anti-myosin heavy chain antibody MF20 in C2C12 cultures treated with plasma from $C, O B$, and OBD patients on day 5 after stimulation. Scale bars represent $100 \mu \mathrm{m}$; (B) width of myotubes in C/OB/OBD-treated cultures, measured in arbitrary units in 5-6 independent photographs; the number of myotubes on each photo was 10-20; (C) proportion of myotubes containing $\geq 6$ nuclei or $<6$ nuclei in C/OB/OBD-treated cultures (\%).

\subsection{Plasma from Obese Patients $(O B)$ and from $O B$ Patients Comorbid with Type 2 Diabetes (OBD) Affects C2C12 Myotubes Bioenergetics}

To investigate the effect of plasma from OB/OBD patients on cellular bioenergetics, a mitochondria stress test was performed on $\mathrm{C} / \mathrm{OB} / \mathrm{OBD}$-treated myotubes. This technique allows quantifying OXPHOS and glycolysis by using a specific protocol designed to target distinct components of these pathways with pharmacological agents. Basal measurements of the mitochondrial respiration rate (OCR) and glycolytic ECAR were performed in C2C12 myotubes treated with C/OB/OBD plasma (Figure 4A,B). The OCR vs. ECAR plot showed increased ECAR in OB-treated myotubes but not in OBD-treated myotubes compared to myotubes treated with plasma from $C$ participants, suggesting a metabolic profile switch to glycolysis in OB- but not in OBD-treated myotubes (Figure 4C). The mitochondrial 
uncoupler BAM15 was used to estimate the maximal respiration rate, and myotubes treated with OBD but not with OB plasma showed a significant decrease in the maximal respiration rate (Figure $4 \mathrm{D})$.

These findings indicate that plasma from OB and OBD patients affected the bioenergetics of $\mathrm{C} 2 \mathrm{C} 12$ myotubes in different ways: while OBD plasma negatively affected the maximal mitochondrial respiration rate, $\mathrm{OB}$ plasma stimulated the metabolic switch to glycolysis.
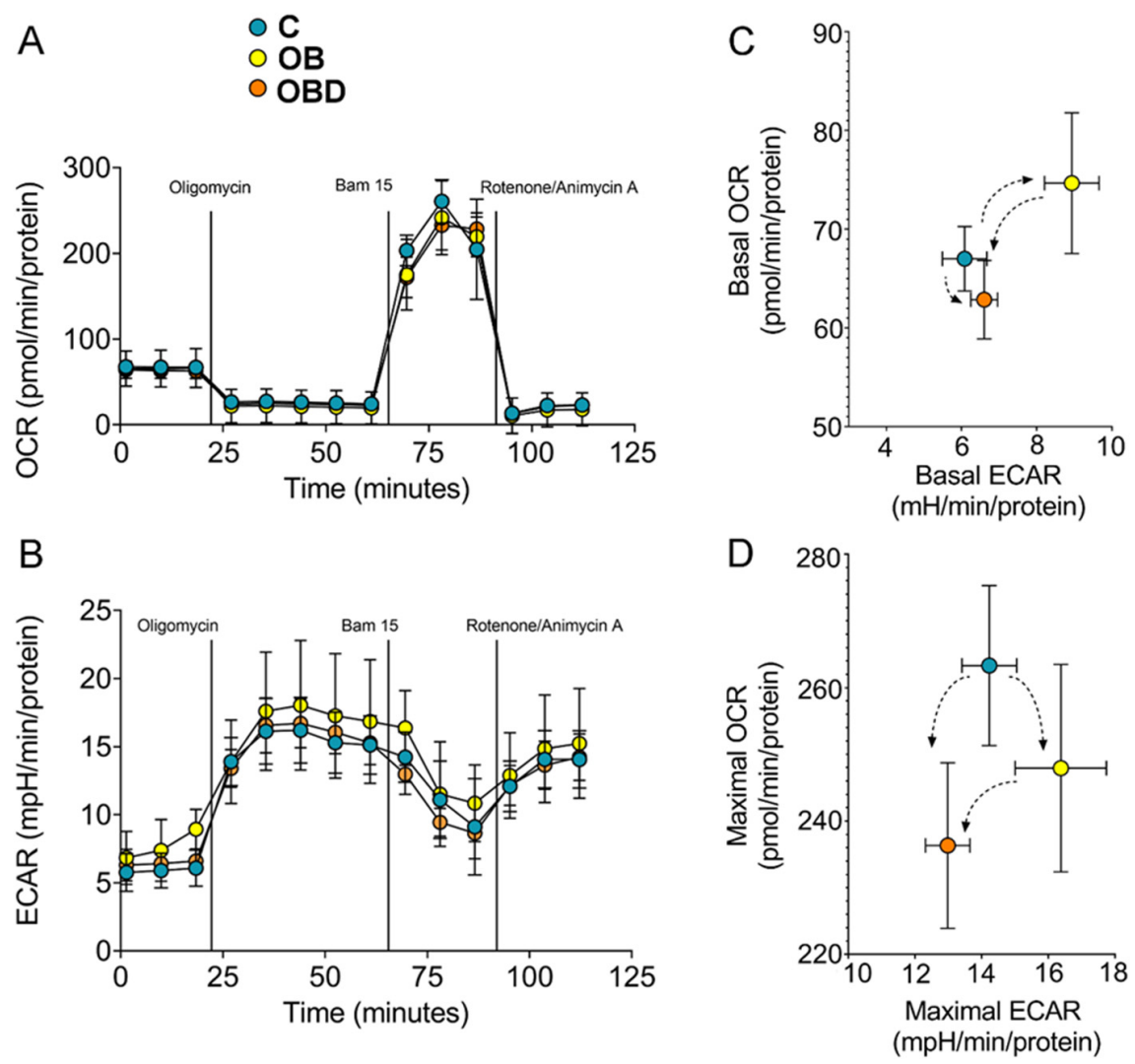

Figure 4. Metabolic profiles of $\mathrm{C} 2 \mathrm{C} 12$ myotubes treated with $\mathrm{C}, \mathrm{OB}$, and OBD plasma. (A) OCR traces for myotubes treated with human plasma, as indicated; (B) kinetic profiles of ECAR for myotubes treated with human plasma, as indicated; (C) basal OCR vs. basal ECAR [mean \pm sem for both parameters]; (D) Maximal Respiratory capacity vs. Maximal Glycolytic capacity [mean \pm sem]. All data were calculated from 6-8 Seahorse microplate wells and were normalized to total protein content in each well.

3.4. Plasma from Obese Patients $(O B)$ and Patients with Type 2 Diabetes Comorbid with Obesity (OBD) Affects the Expression of the Mitochondria Regulators Atgl/Pgc1b/miR378-a-3p

Then, we tested how plasma from obese patients with or without comorbid type 2 diabetes affected the expression of mitochondria regulators using the C2C12 mouse myoblasts differentiation model.

During C2C12 differentiation from day 0 to day 3, the levels of both adipose triglyceride lipase $(A t g l)$ and PPARG coactivator $\left(P_{g c 1 b}\right)$ increased up to 2.4-fold and 1.9-fold, respectively (Figure 5A,B; green label). The plasma of obese patients had a stronger effect on the levels of both Atgl and Pgc1b than the plasma of obese patients with type 2 diabetes. Specifically, the levels of Atgl were downregulated 1.6-fold by plasma from OB patients and 1.2-fold by plasma from OBD patients compared to plasma from healthy volunteers (Figure 5A; blue, yellow, and red labels). The levels of $P_{g c} 1 b$ was downregulated 1.5-fold by plasma from OB patients and remained unchanged after treatment with plasma from OBD patients compared to plasma from healthy volunteers (Figure 5B; blue, yellow, and 
red labels). At the same time, changes in the levels of miR-378a-3p in response to plasma treatment were different-the levels remained unchanged after treatment with plasma from OB patients and were upregulated 2.4-fold by plasma from OBD patients compared to plasma from healthy volunteers (Figure 5C; blue, yellow, and red labels). Positive correlation was observed between levels of Atgl and $P g c 1 b$ both during C2C12 differentiation (Figure 6A) and after plasma treatment (Figure 6B).
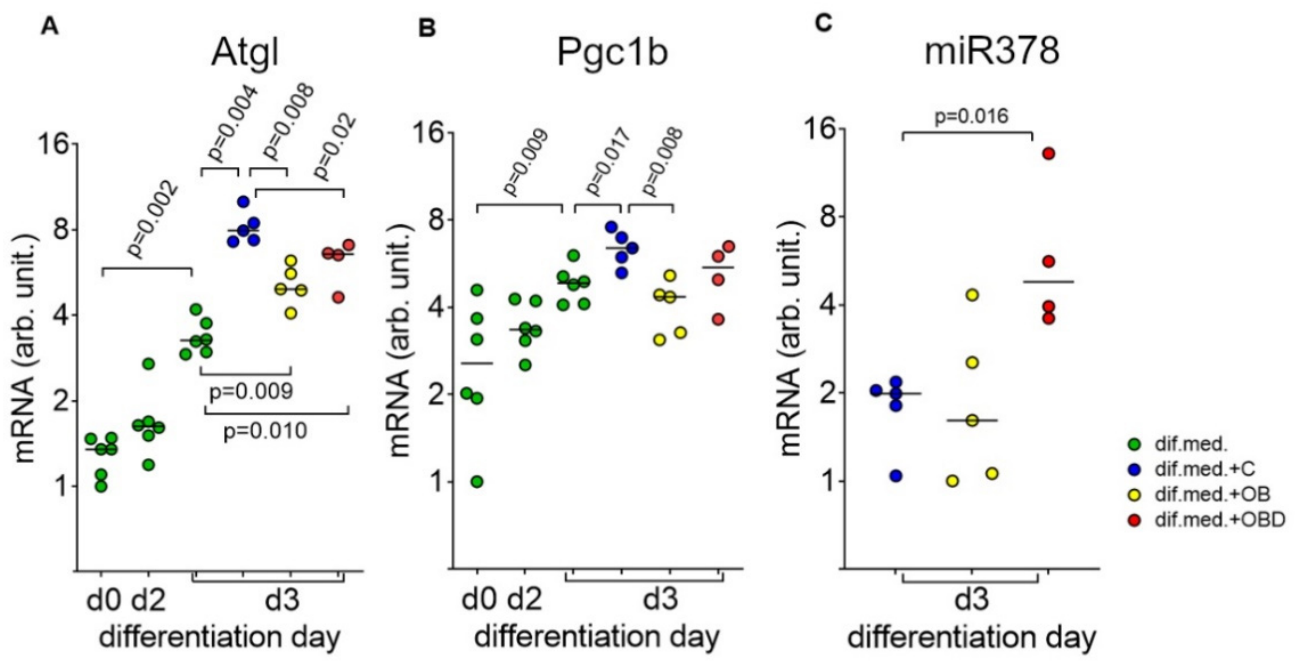

Figure 5. Effects of plasma from healthy volunteers (C), obese patients (OB), and obese patients comorbid with type 2 diabetes (OBD) on ethe xpression of mitochondria regulators in $\mathrm{C} 2 \mathrm{C} 12$ myoblasts. (A) Adipose triglyceride lipase (Atgl); (B) PPARG co-activator $(P g c 1 b)$; (C) miR-378a (miR378a).

A

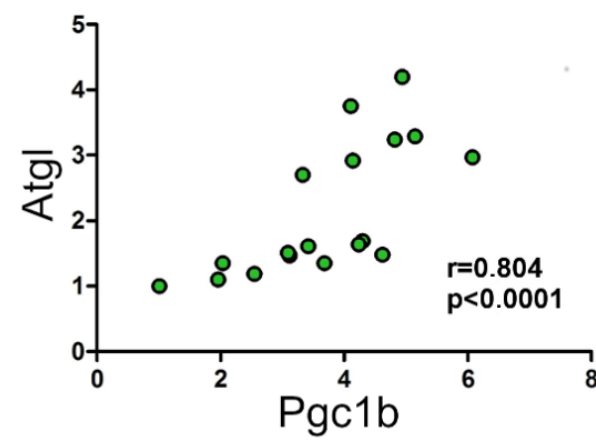

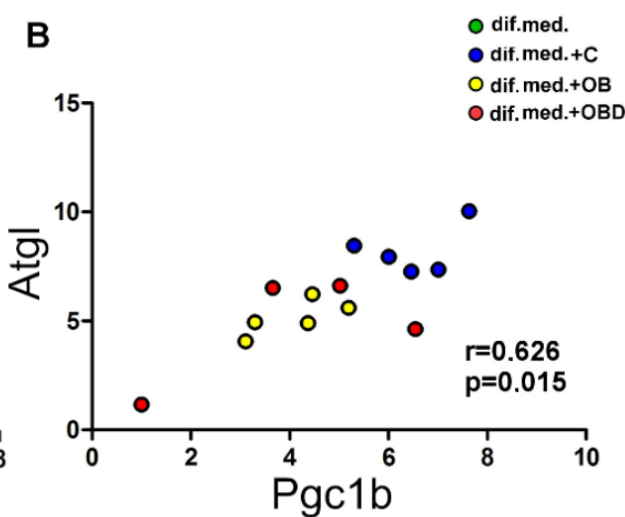

Figure 6. Correlation between the levels of Atgl and those of $P g c 1 b$ (A) during $\mathrm{C} 2 \mathrm{C} 12$ differentiation and (B) after treatment of C2C12 with plasma.

\subsection{Analysis of Existing Databases of mir-378a-3p Potential Targets to Predict Downstream Cellular Processes}

To explore the potential relationship between changes in the level of miR-378a-3p expression and specific cellular processes in skeletal muscle tissue, we analyzed existing databases to characterize the regulatory potential of miR-378-3p. Predicted protein targets of miR-378a-3p were retrieved from TargetScan and miRDB databases. Overlapping targets in these sets, which contained 69 genes, were used for enrichment analysis. The GO Biological Processes associated with predicted targets of miR-378a-3p are presented in Table 3. Notably, among the identified GO Biological Processes, several pathways were related directly to skeletal muscle development, such as "regulation of muscle hypertrophy" and "myoblast differentiation"; the others pathways were related to general metabolic processes, such as "regulation of macromolecule metabolic process", "MAPK cascade", "cellular response to glucocorticoid stimulus". 
Table 3. GO Biological Processes associated with predicted targets of miR-378a-3p.

\begin{tabular}{|c|c|c|}
\hline GO Term & $p$-Value & Predicted Targets of miR-378a-3p \\
\hline ERK1 and ERK2 cascade (GO:0070371) & 0.00005 & MAPK1; IGF1; ZFP36L2 \\
\hline negative regulation of stem cell differentiation (GO:2000737) & 0.00052 & REST; ZFP36L2 \\
\hline nervous system development (GO:0007399) & 0.00096 & $\begin{array}{l}\text { NEUROD1; DSCAM; PAX8; DYRK1A; } \\
\text { DCX; SHANK3; DACT1 }\end{array}$ \\
\hline regulation of macromolecule metabolic process (GO:0060255) & 0.00103 & MAPK1; ALPK3; IGF1; TOB2 \\
\hline positive regulation of muscle hypertrophy (GO:0014742) & 0.00104 & IGF1; IL6ST \\
\hline cellular response to corticosteroid stimulus (GO:0071384) & 0.00120 & REST; ZFP36L2 \\
\hline synapse assembly (GO:0007416) & 0.00135 & NPAS4; DSCAM; SHANK3 \\
\hline positive regulation of cardiac muscle hypertrophy (GO:0010613) & 0.00136 & IGF1; IL6ST \\
\hline myoblast differentiation (GO:0045445) & 0.00136 & REST; IGF1 \\
\hline cellular response to glucocorticoid stimulus (GO:0071385) & 0.00154 & REST; ZFP36L2 \\
\hline peptidyl-serine phosphorylation (GO:0018105) & 0.00159 & DYRK1A; MAPK1; CSNK1G2; CAMKK2 \\
\hline peptidyl-threonine phosphorylation (GO:0018107) & 0.00168 & DYRK1A; MAPK1; CAMKK2 \\
\hline $\begin{array}{l}\text { positive regulation of transcription regulatory region DNA binding } \\
\text { (GO:2000679) }\end{array}$ & 0.00193 & NEUROD1; IGF1 \\
\hline phosphorylation (GO:0016310) & 0.00214 & $\begin{array}{l}\text { TOLLIP; DYRK1A; MAPK1; ALPK3; } \\
\text { CSNK1G2; CAMKK2 }\end{array}$ \\
\hline regulation of cardiac muscle hypertrophy (GO:0010611) & 0.00236 & IGF1; IL6ST \\
\hline MAPK cascade (GO:0000165) & 0.00272 & $\begin{array}{l}\text { MAPK1; IGF1; SHANK3; ZFP36L2; } \\
\text { CAMKK2 }\end{array}$ \\
\hline peptidyl-serine modification (GO:0018209) & 0.00283 & DYRK1A; MAPK1; CSNK1G2; CAMKK2 \\
\hline modulation of chemical synaptic transmission (GO:0050804) & 0.00286 & NPAS4; RIMS4; GRIK3 \\
\hline response to glucocorticoid (GO:0051384) & 0.00308 & REST; ZFP36L2 \\
\hline peptidyl-threonine modification (GO:0018210) & 0.00361 & DYRK1A; MAPK1; CAMKK2 \\
\hline regulation of transcription regulatory region DNA binding (GO:2000677) & 0.00361 & NEUROD1; IGF1 \\
\hline response to hexose (GO:0009746) & 0.00389 & NEUROD1; IGF1 \\
\hline positive regulation of cell differentiation (GO:0045597) & 0.00454 & NEUROD1; PAX8; IGF1; IL6ST \\
\hline positive regulation of gene expression (GO:0010628) & 0.00494 & $\begin{array}{l}\text { NEUROD1; REST; PAX8; DYRK1A; } \\
\text { MAPK1; IGF1; RBMS3; CAMKK2 }\end{array}$ \\
\hline negative regulation of fat cell differentiation (GO:0045599) & 0.00544 & ZFPM2; ZFP36L2 \\
\hline positive regulation of signal transduction (GO:0009967) & 0.00561 & TSPAN17; IGF1; SHANK3; DACT1 \\
\hline protein phosphorylation (GO:0006468) & 0.00561 & $\begin{array}{l}\text { DYRK1A; MAPK1; ALPK3; CSNK1G2; } \\
\text { CAMKK2; MAP2K6 }\end{array}$ \\
\hline regulation of interferon-beta production (GO:0032648) & 0.00613 & YY1; TRAF3 \\
\hline positive regulation of DNA binding (GO:0043388) & 0.00613 & NEUROD1; IGF1 \\
\hline positive regulation of osteoblast differentiation (GO:0045669) & 0.00648 & IGF1; IL6ST \\
\hline epithelium development (GO:0060429) & 0.00737 & PAX8; TOLLIP; DACT1 \\
\hline sphingolipid metabolic process (GO:0006665) & 0.00754 & SERINC1; KDSR; CSNK1G2 \\
\hline activation of MAPK activity (GO:0000187) & 0.00772 & MAPK1; IGF1; MAP2K6 \\
\hline regulation of gene expression (GO:0010468) & 0.00905 & $\begin{array}{l}\text { YY1; REST; ZNF514; MAPK1; ALPK3; } \\
\text { IGF1; TOB2; SRSF10; RBMS3 }\end{array}$ \\
\hline negative regulation of macromolecule metabolic process (GO:0010605) & 0.00905 & YY1; REST; RBMS3 \\
\hline
\end{tabular}




\section{Discussion}

In this work, we showed that plasma from $\mathrm{OB}$ and $\mathrm{OBD}$ patients affects skeletal muscle growth, development, and metabolism. The most important observations made in this study are that $\mathrm{OB} / \mathrm{OBD}$ plasma affects skeletal muscle mitochondrial function.

We showed that treatment of $\mathrm{C} 2 \mathrm{C} 12$ with $\mathrm{OB}$ samples caused a decrease in the expression of the Atgl and Pgclb genes, which suggested that the plasma of these patients contains regulatory molecules that suppress the expression of these genes. At the same time, the energetics of the cells shifted towards glycolysis, probably due to a decrease in the content of fatty acids as a substrate, and the respiration rate of mitochondria was higher than in other samples. Decreased expression of the $P g c 1 b$ gene may also affect the morphology of myotubes, since $P g c 1 a$ and $P g c 1 b$ are known to attenuate protein synthesis and degradation in skeletal muscle through mechanisms dependent on estrogen-related receptor alpha $(E R R \alpha)[37]$.

An increased level of miR-378-3p was found in myotubes treated with OBD plasma. There is evidence that miR-378-3p is involved in mitochondrial energy homeostasis, inhibiting mitochondrial function, and affects the development, differentiation, and regeneration of muscles [38-40]. Bioenergetic analysis using SeaHorse demonstrated that OBD plasma inhibited mitochondrial respiration. This can also be explained by the fact that all OBD patients were on metformin therapy, which impairs mitochondrial respiration. According to the literature, metformin reduces the efficiency of mitochondrial metabolism, leading to a switch to aerobic glycolysis [41-43]. However, in our work, in the samples treated with OBD plasma, there was no shift towards glycolysis; it is probably more difficult for diabetics to shift the balance in this direction. Only changes in the expression of the Atgl gene were observed, as observed also in the samples treated with OB plasma (there was no additional effect of diabetes compared to obesity).

The correlation between Atgl and Pgc1b levels both during C2C12 differentiation and after plasma treatment suggests that these genes form a regulatory unit in different states of $\mathrm{C} 2 \mathrm{C} 12$ cells. The absence of a positive correlation between the levels of $P g c 1 b$ and those of its encoded intron miR-378-3p confirms the recent discovery that miR-378 has its own transcription apparatus [44].

We believe that the system used in this work (model of skeletal muscle cells + shortterm exposure to readily available plasma samples of patients) may be useful for predicting the state of skeletal muscle in patients with metabolic disorders.

Indeed, the changes in mitochondrial functions that we observed in $\mathrm{C} 2 \mathrm{C} 12$ are consistent with known changes in patients' skeletal muscles, namely, stronger impairment of skeletal muscle mitochondrial function in obese patients with diabetes compared to obese patients without diabetes [45-47].

It is noteworthy that all the studied targets are involved in the regulation of fatty acid oxidation: Atgl provides a controlled release of fatty acids [27], $P g c 1 b$ acts as an activator of fatty acid oxidation [48], and miR-378-3p acts as an inhibitor [30]. The observed changes in the levels of each target have a negative regulatory effect on fatty acid oxidation, which is consistent with the fact that mitochondrial fatty acid oxidation is reduced in skeletal muscle of diabetic patients $[49,50]$. The accumulation of lipids in skeletal muscle decreases their insulin sensitivity [51].

The effects of Atgl on mitochondria functions seem to be tissue-specific. In the heart, FFA produced by Atgl is involved in PPARa activation, which regulates mitochondrial FFA oxidation and prevents lipid accumulation in the myocardium [26], whereas in skeletal muscle, no alteration in mitochondrial content or respiration functions were found after manipulation of $A \operatorname{tgl} l$ levels in mouse models [52,53]. On the other hand, the use of the C2C12 skeletal muscle cell model allowed to reveal a link between Atgl and mitochondrial functions (Atgl overexpression was shown to increase lipolysis from intramyocellular lipid droplets, activate transcriptional responses (PPARd and its target Pgc1a) to enhance mitochondrial fatty acid oxidative capacity, and protect against the deleterious effect of 
high fat levels on mitochondria function), probably due to the lack of overlap with other metabolic pathways which are active in animal models [54,55].

Two types of the changes in gene expression were identified: (i) one type, common to plasma from both groups of patients, was a decrease in Atgl levels, and (ii) the other type, specific for plasma from obese and diabetic patients, was an increase in miR-378-3p levels. Figure 7 shows a suggested model of the possible effect of patient plasma on mitochondrial function and levels of its regulators, which summarizes our results and literature data. Earlier, it was shown that $A t g l$ has an indirect positive effect on mitochondrial functions [56], while miR-378-3p negatively regulates the function of mitochondria [30]. Therefore, it can be assumed that when $\mathrm{C} 2 \mathrm{C} 12$ are exposed to plasma of obese and diabetic patients, both identified components combine, and their synergistic action causes a stronger dysfunction of mitochondria.
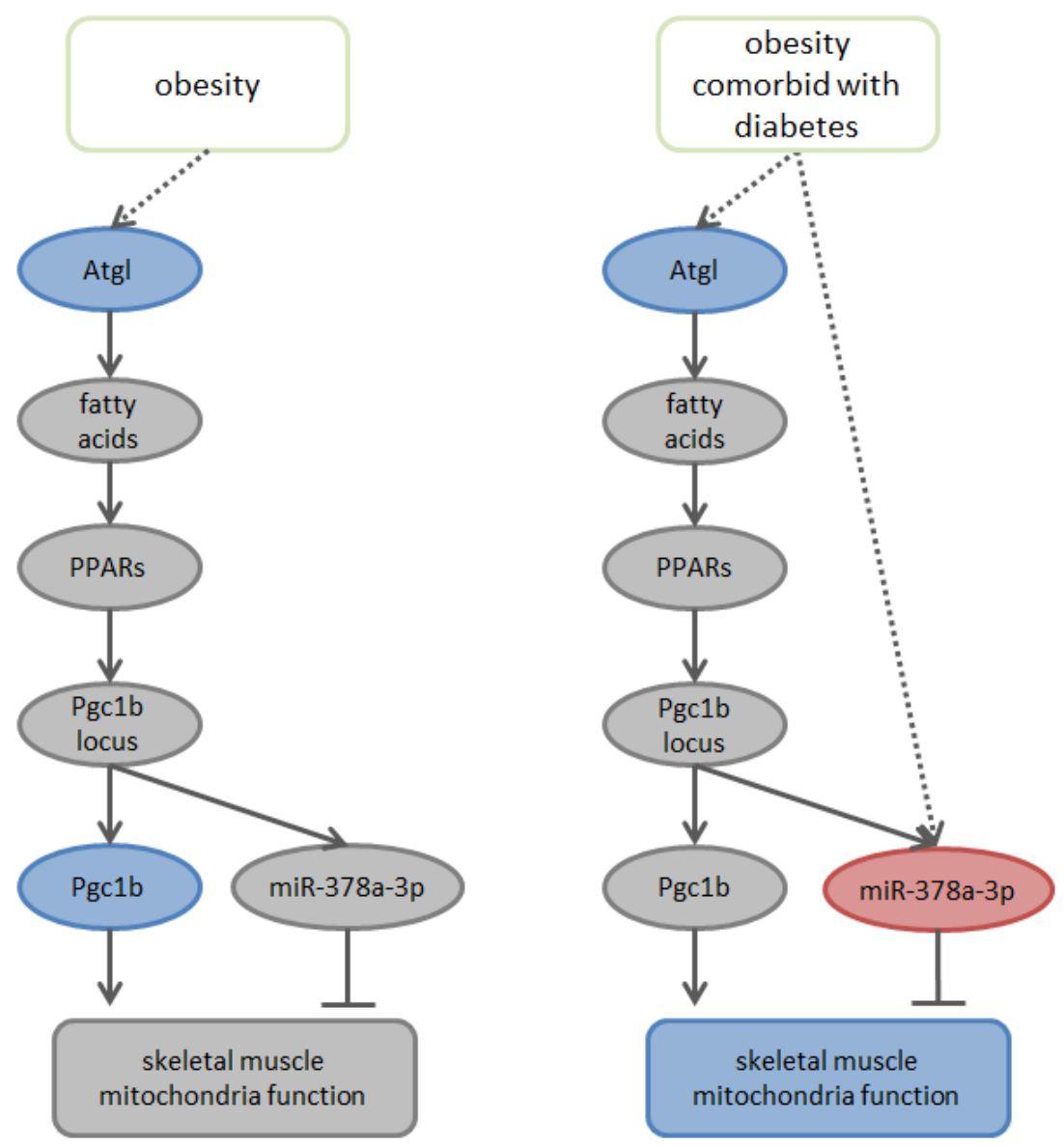

Figure 7. Proposed model of patients' plasma effects on mitochondria function and on the levels of its regulators. (Blue and red-observed down- and up-regulation).

Enrichment analysis data suggest that miR-378-3p may also interfere with MAPK signaling pathway through MAPK1 (p38 Map kinase), known to be involved in the regulation of myogenesis, as suggested by the link between ROS, accumulating in proliferating satellite cells, and activation of p38 $\alpha$ MAP kinase leading to satellite cell differentiation [56]. The dysregulation of p38 Map kinase signaling contributes to skeletal muscle wasting, sarcopenia, and skeletal muscle stem cells premature senescence [57]. These mechanisms might provide the link between miR-378a-3p, mitochondrial dysfunction, and functional metabolic alterations in skeletal muscle in obese patients with TDM2. Further investigations are required to clarify this issue.

In conclusion, we demonstrated here that, even during short-term exposure, plasma from patients with obesity and obesity comorbid with diabetes possess disease-specific 
regulatory action towards differentiation characteristics and bioenergetics properties of C2C12 myoblasts.

The study has potential limitations that could be addressed in future research. First, difference in age between the control and OB or OBD groups can introduce a bias, when analyzing the data between control and OB or OBD groups. Second, some small differences between groups may be missed due to small number of enrolled patients. Third, the present investigation lack data on such metabolic parameters as triglycerides and HDL-cholesterol.

Author Contributions: Conceptualization, A.V.F. and R.I.D.; Data curation, A.V.F., M.S.A., A.D.A., and A.E.N.; Formal analysis, N.V.K., A.V.F., Y.M. and E.V.I.; Funding acquisition, A.Y.B.; Investigation, N.V.K., Y.M., K.A.K., S.S.P. and E.V.I.; Methodology, N.V.K., Y.M., K.A.K., S.S.P. and E.V.I.; Project administration, A.V.F.; Supervision, A.A.K., A.Y.B., and R.I.D.; Validation, A.V.F., Y.M., and E.V.I.; Visualization, N.V.K., Y.M., S.S.P. and E.V.I.; Writing-original draft, N.V.K. and A.V.F.; Writingreview \& editing, N.V.K., A.V.F., A.A.K., A.Y.B. and R.I.D. All authors have read and agreed to the published version of the manuscript.

Funding: This work was financially supported by the Ministry of Science and Higher Education of the Russian Federation (Agreement No. 075-15-2020-901).

Institutional Review Board Statement: The study was conducted according to the guidelines of the Declaration of Helsinki, and approved by the Ethics Committee of the Almazov National Medical Research Centre (Ref. \# 54/14.03.2016).

Informed Consent Statement: All patients entering the program agreed to and signed an institutional review board-approved statement of informed consent.

Data Availability Statement: Publicly available datasets were analyzed in this study. This data can be found here: [http:/ / www.targetscan.org/, accessed on 20 May 2021; http:/ / mirdb.org/, accessed on 20 May 2021]. The data presented in this study are available on request from the corresponding author. The data are not publicly available due to privacy restrictions.

Conflicts of Interest: The authors declare no conflict of interest.

\section{References}

1. Arroyo-Johnson, C.; Mincey, K.D. Obesity Epidemiology Worldwide. Gastroenterol. Clin. N. Am. 2016, 45, 571-579. [CrossRef]

2. Guariguata, L.; Whiting, D.R.; Hambleton, I.; Beagley, J.; Linnenkamp, U.; Shaw, J.E. Global estimates of diabetes prevalence for 2013 and projections for 2035. Diabetes Res. Clin. Pract. 2014, 103, 137-149. [CrossRef] [PubMed]

3. Lehr, S.; Hartwig, S.; Sell, H. Adipokines: A treasure trove for the discovery of biomarkers for metabolic disorders. Proteom. Clin. Appl. 2012, 6, 91-101. [CrossRef] [PubMed]

4. Fasshauer, M.; Blüher, M. Adipokines in health and disease. Trends Pharmacol. Sci. 2015, 36, 461-470. [CrossRef]

5. Jallut, D.; Golay, A.; Munger, R.; Frascarolo, P.; Schutz, Y.; Jéquier, E.; Felber, J.P. Impaired glucose tolerance and diabetes in obesity: A 6-year follow-up study of glucose metabolism. Metabolism 1990, 39, 1068-1075. [CrossRef]

6. Teasdale, N.; Martin, S.; Philippe, C.; Grant, H.; Angelo, T.; Olivier, H. Obesity alters balance and movement control. Curr. Obes. Rep. 2013, 2, 235-240. [CrossRef]

7. Prado, C.; Lieffers, J.; McCargar, L.; Reiman, T.; Sawyer, M.; Martin, L.; Baracos, V. Prevalence and clinical implications of sarcopenic obesity in patients with solid tumours of the respiratory and gastrointestinal tracts: A population-based study. Lancet 2008, 9, 629-635. [CrossRef]

8. Tallis, J.; James, R.; Seebacher, F. The effects of obesity on skeletal muscle contractile function. J. Exp. Biol. 2018, 221, jeb163840. [CrossRef]

9. Tanner, C.J.; Barakat, H.; Dohm, G.; Pories, W.; MacDonald, K.; Cunningham, P.; Swanson, M.; Houmard, J. Muscle fiber type is associated with obesity and weight loss. Am. J. Physiol. Endocrinol. Metab. 2002, 282, E1191-E1196. [CrossRef]

10. De Wilde, J.; Mohren, R.; van den Berg, S.; Boekschoten, M.; Willems-Van Dijk, K.; de Groot, P.; Müller, M.; Mariman, E.; Smit, E. Short-term high fat-feeding results in morphological and metabolic adaptations in the skeletal muscle of C57BL/6J mice. Physiol. Genom. 2008, 32, 360-369. [CrossRef]

11. Helge, J.; Fraser, A.; Kriketos, A.; Jenkins, A.; Calvert, G.; Ayere, K.; Storlien, L. Interrelationships between muscle fibre type, substrate oxidation and body fat. Int. J. Obes. 1999, 23, 986-991. [CrossRef] [PubMed]

12. Stuart, C.; McCurry, M.; Marino, A.; South, M.; Howell, M.; Layne, A.; Ramsey, M.; Stone, M. Slow-twitch fiber proportion in skeletal muscle correlates with insulin responsiveness. J. Clin. Endocrinol. Metab. 2013, 98, 2027-2036. [CrossRef] [PubMed]

13. Akhmedov, D.; Berdeaux, R. The effects of obesity on skeletal muscle regeneration. Front. Physiol. 2013, 4, 1-12. [CrossRef] [PubMed] 
14. D'Souza, D.; Trajcevski, K.; Al-Sajee, D.; Wang, D.; Thomas, M. Diet-induced obesity impairs muscle satellite cell activation and muscle repair through alterations in hepatocyte growth factor signaling. Physiol. Rep. 2015, 3, e12506. [CrossRef] [PubMed]

15. Sexton, W.L.; Poole, D.C.; Mathieu-Costello, O. Microcirculatory structure-function relationships in skeletal muscle of diabetic rats. Am. J. Physiol. 1994, 266, H1502-H1511. [PubMed]

16. Andersen, H.; Gadeberg, P.C.; Brock, B.; Jakobsen, J. Muscular atrophy in diabetic neuropathy: A stereological magnetic resonance imaging study. Diabetologia 1997, 40, 1062-1069. [CrossRef]

17. Kamei, Y.; Miura, S.; Suzuki, M.; Kai, Y.; Mizukami, J.; Taniguchi, T.; Mochida, K.; Hata, T.; Matsuda, J.; Aburatani, H.; et al. Skeletal muscle foxo1 (FKHR) transgenic mice have less skeletal muscle mass, down-regulated type I (slow twitch/red muscle) fiber genes, and impaired glycemic control. J. Biol. Chem. 2004, 279, 41114-41123. [CrossRef]

18. Hickey, M.S.; Carey, J.O.; Azevedo, J.L.; Houmard, J.A.; Pories, W.J.; Israel, R.G.; Dohm, G.L. Skeletal muscle fiber composition is related to adiposity and in vitro glucose transport rate in humans. Am. J. Phys. 1995, 268, E453-E457. [CrossRef]

19. Oberbach, A.; Bossenz, Y.; Lehmann, S.; Niebauer, J.; Adams, V.; Paschke, R.; Schon, M.R.; Bluher, M.; Punkt, K. Altered fiber distribution and fiber-specific glycolytic and oxidative enzyme activity in skeletal muscle of patients with type 2 diabetes. Diabetes Care 2006, 29, 895-900. [CrossRef]

20. Greco, A.V.; Tataranni, P.A.; Mingrone, G.; de Gaetano, A.; Manto, A.; Cotroneo, P.; Ghirlanda, G. Daily energy metabolism in patients with type 1 diabetes mellitus. J. Am. Coll. Nutr. 1995, 14, 286-291. [CrossRef]

21. Brandenburg, S.L.; Reusch, J.E.; Bauer, T.A.; Jeffers, B.W.; Hiatt, W.R.; Regensteiner, J.G. Effects of exercise training on oxygen uptake kinetic responses in women with type 2 diabetes. Diabetes Care 1999, 22, 1640-1646. [CrossRef] [PubMed]

22. Fujimaki, S.; Kuwabara, T. Diabetes-Induced Dysfunction of Mitochondria and Stem Cells in Skeletal Muscle and the Nervous System. Int. J. Mol. Sci. 2017, 18, 2147. [CrossRef] [PubMed]

23. Regensteiner, J.G.; Sippel, J.; McFarling, E.T.; Wolfel, E.E.; Hiatt, W.R. Effects of non-insulin-dependent diabetes on oxygen consumption during treadmill exercise. Med. Sci. Sport. Exerc. 1995, 27, 875-881. [CrossRef]

24. Yokota, T.; Kinugawa, S.; Hirabayashi, K.; Matsushima, S.; Inoue, N.; Ohta, Y.; Hamaguchi, S.; Sobirin, M.A.; Ono, T.; Suga, T.; et al. Oxidative stress in skeletal muscle impairs mitochondrial respiration and limits exercise capacity in type 2 diabetic mice. Am. J. Physiol. Heart Circ. Physiol. 2009, 297, 1069-1077. [CrossRef]

25. Pinti, M.V.; Fink, G.K.; Hathaway, Q.A.; Durr, A.J.; Kunovac, A.; Hollander, J.M. Mitochondrial dysfunction in type 2 diabetes mellitus: An organ-based analysis. Am. J. Physiol. Metab. 2019, 316, E268-E285. [CrossRef]

26. Haemmerle, G.; Moustafa, T.; Woelkart, G. ATGL-mediated fat catabolism regulates cardiac mitochondrial function via PPARalpha and PGC-1. Nat. Med. 2011, 17, 1076-1085. [CrossRef]

27. Zechner, R.; Kienesberger, P.C.; Haemmerle, G.; Zimmermann, R.; Lass, A. Adipose triglyceride lipase and the lipolytic catabolism of cellular fat stores. J. Lipid Res. 2009, 50, 3-21. [CrossRef]

28. Kliewer, S.A.; Xu, H.E.; Lambert, M.H.; Willson, T.M. Peroxisome proliferator-activated receptors: From genes to physiology. Recent Prog. Horm. Res. 2001, 56, 238-263. [CrossRef]

29. Finck, B.N.; Kelly, D.P. PGC-1 coactivators: Inducible regulators of energy metabolism in health and disease. J. Clin. Investig. 2006, 116, 615-622. [CrossRef]

30. Carrer, M.; Liu, N.; Grueter, C.E.; Williams, A.H.; Frisard, M.I.; Hulver, M.W.; Bassel-Duby, R.; Olson, E.N. Control of mitochondrial metabolism and systemic energy homeostasis by microRNAs 378 and 378. Proc. Natl. Acad. Sci. USA 2012, 109, 15330-15335. [CrossRef]

31. Kondratov, K.; Nikitin, Y.; Fedorov, A.; Kostareva, A.; Mikhailovskii, V.; Isakov, D.; Ivanov, A.; Golovkin, A. Heterogeneity of the nucleic acid repertoire of plasma extracellular vesicles demonstrated using high-sensitivity fluorescence-activated sorting. J. Extracell. Vesicles 2020, 9, 1743139. [CrossRef]

32. Agarwal, V.; Bell, G.W.; Nam, J.; Bartel, D.P. Predicting effective microRNA target sites in mammalian mRNAs. eLife 2015, 4, e05005. [CrossRef]

33. Chen, Y.; Wang, X. miRDB: An online database for prediction of functional microRNA targets. Nucleic Acids Res. 2020, 48, D127-D131. [CrossRef]

34. Chen, E.Y.; Tan, C.M.; Kou, Y.; Duan, Q.; Wang, Z.; Meirelles, G.V.; Clark, N.R.; Ma'ayan, A. Enrichr: Interactive and collaborative HTML5 gene list enrichment analysis tool. BMC Bioinf. 2013, 14, 128. [CrossRef]

35. Bentzinger, C.F.; Wang, Y.X.; Rudnicki, M.A. Building Muscle: Molecular Regulation of Myogenesis. Cold Spring Harb. Perspect. Biol. 2012, 4, a008342. [CrossRef] [PubMed]

36. Sampath, S.C.; Sampath, S.C.; Millay, D.P. Myoblast fusion confusion: The resolution begins. Skelet. Muscle 2018, 8, 3. [CrossRef] [PubMed]

37. Brown, E.L.; Foletta, V.C.; Wright, C.R.; Sepulveda, P.V.; Konstantopoulos, N.; Sanigorski, A.; Della Gatta, P.; Cameron-Smith, D.; Kralli, A.; Russell, A.P. PGC- $1 \alpha$ and PGC-1 $\beta$ increase protein synthesis via ERR $\alpha$ in C2C12 myotubes. Front. Physiol. 2018, 9, 1336. [CrossRef] [PubMed]

38. Krist, B.; Florczyk, U.; Pietraszek-Gremplewicz, K.; Józkowicz, A.; Dulak, J. The Role of miR-378a in Metabolism, Angiogenesis, and Muscle Biology. Int. J. Endocrinol. 2015, 2015, 281756. [CrossRef]

39. Gagan, J.; Dey, B.K.; Layer, R.; Yan, Z.; Dutta, A. MicroRNA-378 Targets the Myogenic Repressor MyoR during Myoblast Differentiation. J. Biol. Chem. 2011, 286, 19431-19438. [CrossRef] 
40. Hou, X.; Tang, Z.; Liu, H.; Wang, N.; Ju, H.; Li, K. Discovery of MicroRNAs Associated with Myogenesis by Deep Sequencing of Serial Developmental Skeletal Muscles in Pigs. PLoS ONE 2012, 7, e52123. [CrossRef]

41. Hur, K.Y.; Lee, M. New mechanisms of metformin action: Focusing on mitochondria and the gut. J. Diabetes Investig. 2015, 6, 600-609. [CrossRef] [PubMed]

42. Andrzejewski, S.; Gravel, S.-P.; Pollak, M.; St-Pierre, J. Metformin directly acts on mitochondria to alter cellular bioenergetics. Cancer Metab. 2014, 2, 12. [CrossRef] [PubMed]

43. Wessels, B.; Ciapaite, J.; Van Den Broek, N.M.A.; Nicolay, K.; Prompers, J.J. Metformin impairs mitochondrial function in skeletal muscle of both lean and diabetic rats in a Dose-dependent manner. PLoS ONE 2014, 9, e100525. [CrossRef]

44. Zhang, T.; Duan, J.; Zhang, L.; Li, Z.; Steer, C.J.; Yan, G.; Song, G. LXR $\alpha$ Promotes Hepatosteatosis in Part Through Activation of MicroRNA-378 Transcription and Inhibition of Ppargc1 $\beta$ Expression. Hepatology 2019, 69, 1488-1503. [CrossRef] [PubMed]

45. Mogensen, M.; Sahlin, K.; Fernström, M.; Glintborg, D.; Vind, B.F.; Beck-Nielsen, H.; Højlund, K. Mitochondrial respiration is decreased in skeletal muscle of patients with type 2 diabetes. Diabetes 2007, 56, 1592-1599. [CrossRef] [PubMed]

46. Rabøl, R.; Larsen, S.; Højberg, P.M.V.; Almdal, T.; Boushel, R.; Haugaard, S.B.; Andersen, J.L.; Madsbad, S.; Dela, F. Regional anatomic differences in skeletal muscle mitochondrial respiration in type 2 diabetes and obesity. J. Clin. Endocrinol. Metab. 2010, 95, 857-863. [CrossRef] [PubMed]

47. Hesselink, M.K.C.; Schrauwen-Hinderling, V.; Schrauwen, P. Skeletal muscle mitochondria as a target to prevent or treat type 2 diabetes mellitus. Nat. Rev. Endocrinol. 2016, 12, 633-645. [CrossRef] [PubMed]

48. Chambers, K.T.; Chen, Z.; Crawford, P.A.; Fu, X.; Burgess, S.C.; Lai, L.; Leone, T.C.; Kelly, D.P.; Finck, B.N. Liver-Specific PGC-1beta Deficiency Leads to Impaired Mitochondrial Function and Lipogenic Response to Fasting-Refeeding. PLoS ONE 2012, 7, e52645. [CrossRef]

49. Zorzano, A.; Hernández-Alvarez, M.I.; Palacín, M.; Mingrone, G. Alterations in the mitochondrial regulatory pathways constituted by the nuclear co-factors PGC- $1 \alpha$ or PGC- $1 \beta$ and mitofusin 2 in skeletal muscle in type 2 diabetes. Biochim. Biophys. Acta Bioenerg. 2010, 1797, 1028-1033. [CrossRef]

50. Bruce, C.R.; Anderson, M.J.; Carey, A.L.; Newman, D.G.; Bonen, A.; Kriketos, A.D.; Cooney, G.J.; Hawley, J.A. Muscle Oxidative Capacity Is a Better Predictor of Insulin Sensitivity than Lipid Status. J. Clin. Endocrinol. Metab. 2003, 88, 5444-5451. [CrossRef]

51. Park, S.S.; Seo, Y.K. Excess accumulation of lipid impairs insulin sensitivity in skeletal muscle. Int. J. Mol. Sci. 2020, 21, 1949. [CrossRef]

52. Huijsman, E.; van de Par, C.; Economou, C. Adipose triacylglycerol lipase deletion alters whole body energy metabolism and impairs exercise performance in mice. Am. J. Physiol. Endocrinol. Metab. 2009, 297, E505-E513. [CrossRef]

53. Sitnick, M.T.; Basantani, M.K.; Cai, L.; Schoiswohl, G.; Yazbeck, C.F.; Distefano, G.; Ritov, V.; DeLany, J.P.; Schreiber, R.; Stolz, D.B.; et al. Skeletal muscle triacylglycerol hydrolysis does not influence metabolic complications of obesity. Diabetes 2013, 62, 3350-3361. [CrossRef]

54. Meex, R.C.R.; Hoy, A.J.; Mason, R.M. ATGL-mediated triglyceride turnover and the regulation of mitochondrial capacity in skeletal muscle. Am. J. Physiol. Endocrinol. Metab. 2015, 308, E960-E970. [CrossRef] [PubMed]

55. Lettieri-Barbato, D.; Cannata, S.M.; Casagrande, V.; Ciriolo, M.R.; Aquilano, K. Time-controlled fasting prevents aging-like mitochondrial changes induced by persistent dietary fat overload in skeletal muscle. PLoS ONE 2018, 13, e0195912. [CrossRef]

56. L'Honoré, A.; Commère, P.H.; Negroni, E.; Pallafacchina, G.; Friguet, B.; Drouin, J.; Buckingham, M.; Montarras, D. The role of Pitx 2 and Pitx3 in muscle 1 stem cells gives new insights into P38 $\alpha$ MAP kinase and redox regulation of muscle regeneration. eLife 2018, 7, e32991. [CrossRef]

57. Corbel, S.Y.; Llewellyn, M.E.; Mourkioti, F.; Porpiglia, E.; Delp, S.L.; Gilbert, P.M.; Blau, H.M.; Cosgrove, B.D.; Lee, S.P. Rejuvenation of the muscle stem cell population restores strength to injured aged muscles. Nat. Med. 2014, 20, 255-264. 